\title{
Carbon Emission Market Modeling and Simulation Based on Complex Adaptive System Theory
}

\author{
Hu Dong-Bin, Li Cai-Feng* and Cai Hong-Peng
}

School of Business, Central South University; Collaborative Innovation Center of Resource-Conserving \& Environmentfriendly Society and Ecological Civilization, Changsha, Hunan 410083, China

\begin{abstract}
Carbon Emission Trading (CET) Market is a complex and dynamic system involving multiple participants, variety of behavioral decisions and numerous economic, government policy and others. Behaviors which are influenced by the changes in the market will also affect the performance and development of the market. Making a prototype of China's current CET market, attributes, behavior rules and decision models of agents are designed applying complex systems modeling and simulation, combined with object-oriented analysis. A CET market simulation system is built based on SWARM to simulate and analysis the dynamic actors in CET market by transferring the related modules. To examine the validity and accuracy, Shanghai CET market is simulated as an experiment.
\end{abstract}

Keywords: Carbon emission trading, complex system, object-oriented, simulation.

\section{INTRODUCTION}

To resolve the increasingly serious problem of global warming, countries around the world advance the greenhouse gas (GHG) emission reduction actively. As one of the largest emitters, Chinese government has promised to reduce the carbon dioxide emissions per unit of GDP (carbon intensity) by $40 \%-45 \%$ of that in 2005 by 2020 . However, China is in a period of rapid economic development, it is inevitable and obvious to produce massive carbon emissions in the case of growing fossil energy demands. The government has to take effective measures to lower emissions. The European Union Emissions Trading System (EU ETS) with the relatively mature mechanism is the world's largest carbon market. In the first stage, $95 \%$ of the allowances allocated to Member States for free, and then reduced to $90 \%$ in the second stage; from 2013 , at least $50 \%$ of the allowances need to acquire by auction; and by 2020, all allowances of the power industry obtained through auction; all allowances of each sector offered via auction by 2027. Although the EU ETS has made some achievements, allowances in the market are gradually saturated because of exceeding initial allocation, and this situation will remains for several years. Much worse, it'll cause long-term carbon price slump, low efficiency of the carbon trading market and weaken the value of CET mechanism greatly. Therefore, to design the scientific and reasonable CET mechanism for China is not only helpful to establish and strengthen the China's CET market, control carbon dioxide emissions and achieve the emission reduction goal, but also advantageous to integrate with the international CET market and hold discourse right.
The CET market is a complex and dynamic system, traditional economic modeling and analysis means have been unable to analysis the complex behaviors. However, the Agent-Based Modeling and Simulation (ABMS) based on Complex Adaptive System (CAS) theory is an efficient way to analysis this type of system with numerous factors, significant individual differences, complex interactions and diverse rules. The extant researches have been using ABMS to analyze the CET market can be divided into three categories: (1) International carbon emission market analysis. Mutlu et al. (2011) established a JADE (Java Based Agent Development Environment) multi-agent model to analysis the transaction costs, profits and the emission reductions between Annex I and non-Annex I countries under different scenarios [1]. Stańczak (2013) proposed an improved agentbased CET market model to analysis the transaction volume and price in different situations [2]. Mizuta et al. (2001) proposed a simulation framework named Artificial Society with Interacting Agents (ASIA), including online auctions, dynamic global greenhouse gas emissions trading and market simulations three modules. The study simulated the emission trading between different countries, and analyzed abatement costs and strategy options by using the GHG emissions trading module [3]. (2) The potential impact CET on the sectors, especially in the power sector. Chappin et al. (2007) analyzed the impact of EU ETS on the power system based on an agent-based model [4]. Cong and Wei (2010) proposed an electricity market model under the CET mechanism. Their research analyzed the potential impact of CET on Chinese power sector including the discharge costs, electricity price, energy structure and other aspects [5]. LIU et al. (2013) proposed a low-carbon electricity market model. The study indicated the total amount of power industry emission could be controlled effectively by the regulating carbon warrant price and the total amount of carbon emissions limits of conven- 


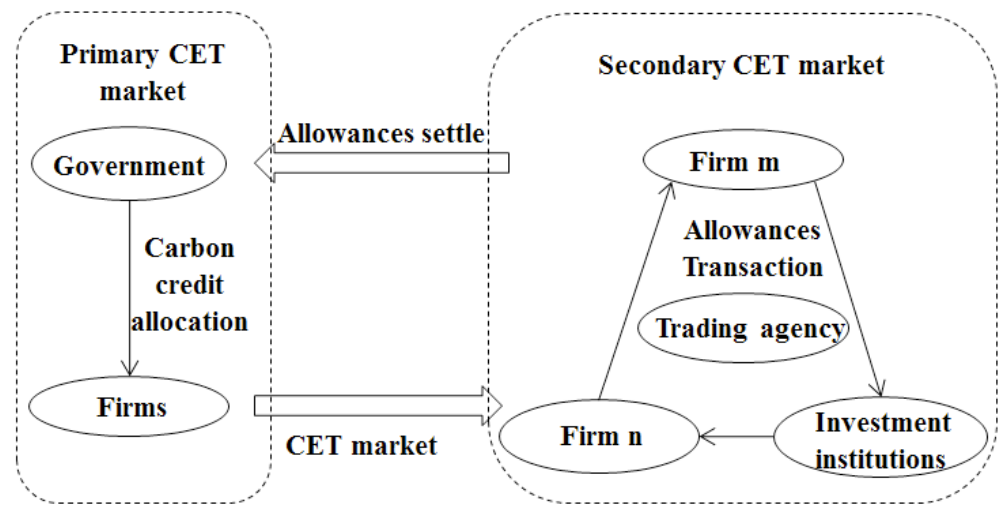

Fig. (1). Interaction diagram of agents.

\begin{tabular}{|c|c|c|c|}
\hline Government & Firm(i) & Investment institutions (j) & Trading agency \\
\hline +Register of Quota & $\begin{array}{l}\text { +Firm name: } \mathrm{F}_{-} \text {Name } \\
\text { +Industry type: } \mathrm{I} \\
\text { + Industry benchmark values: } \mathrm{B}_{\mathrm{i}, \mathrm{T}} \\
\text { +Funding account: } \mathrm{F}_{\mathrm{i}} \\
\text { + Current quota: } \mathrm{AQ}_{\mathrm{i}, \mathrm{T}} \\
\text { + Current emission: } \mathrm{AE}_{\mathrm{i}, \mathrm{T}}\end{array}$ & $\begin{array}{l}\text { +Agency name: } A_{-} \text {Name } \\
\text { +Funding account: } F_{j} \\
\text { +Total quota: } Q_{j}\end{array}$ & \\
\hline $\begin{array}{l}\text { +Total amount determination( () } \\
\text { +Carbon credit allocation () } \\
\text { +Allowances settle () } \\
\text { +Superovulation penalty () }\end{array}$ & $\begin{array}{l}\text { +Emission control needs analysis( ) } \\
\text { +Carbon credit transactions( ) } \\
\text { +Compliance reporting ( ) }\end{array}$ & $\begin{array}{l}\text { +Transaction determination () } \\
\text { +Benefits calculation () }\end{array}$ & $\begin{array}{l}\text { +Setting trading rules () } \\
\text { +Managing transactions () } \\
\text { +Providing trade information () }\end{array}$ \\
\hline
\end{tabular}

Fig. (2). Class diagram of agents.

tional energy generation [6]. Wang et al. (2009) analyzed the interaction between carbon emission market and electricity market. According to the agent-based model, questions such as how many allowances should be allocated, how Generation companies would react to market price and how the price of allowances should affect the profits of Generation companies can be studied [7]. (3) Modeling research on China's CET market, the issues of transaction costs, allowance price and others are analyzed, the influence of the CET on economy and environment are also analyzed. Deng et al. (2013) presented a multi-agent model, impacts on the total transaction costs were analyzed from the change of total emissions reduction, average price and allowances supplydemand [8]. Tang et al. (2015) proposed China's CET market model, different allowance allocation mechanism and punishment mechanism were designed to investigate the influence of CET on China's environment and economy [9].

Although lots of scholars have taken on the research of CET market using the agent-based model, but the behavior and activities of agents in the model and the actual market are quite different: (1) Extant researches focus on activities of the government and firms, ignoring the trading agency, financial and investment institutions, their status and influence in the market; (2) Prediction and learning ability of transaction participants were neglected; behaviors of agents, such as allowance allocation, transaction and other activities, were not consistent with the China's real market. Therefore, it's still necessary to establish a simulation market which is similar to the actual situation. This is exactly the purpose of this paper.

\section{METHODS}

\subsection{Model Framework}

In the proposed model, four main types of agents are involved: government, firms, trading agency and financial and investment institutions. Under the CET scheme, agents would interact with each other through two main markets, i.e., primary carbon trading market and secondary trading market. Fig. (1) illustrates the interaction of agents under the CET scheme.

Government, firms, trading agency and financial and investment institutions are the central agents of the model. Their main attributes and behaviors are listed in Fig. (2).

(1) The government, as the market manager, allocates free allowances to related firms. Register of Quota, the core attributes of government, is used to record the basic information and quotas of firms and check the firms' reducing performance.

(2) The firms, as the CET-targeted agents, carry out a series of activities around quotas caused by CET policy.

(3) Financial and investment institutions are one of the core agents in the market. Their behaviors play an important role to promote the transaction activity.

(4) The trading agency, as an intermediary, provides the trading rules and information.

\subsection{Government}

As the CET policy supervisor and maker, the main behaviors of government including total emission reduction 
target and allowances determination, quotas allocation in primary CET market, allowance settle and superovulation penalties, as showed in Fig. (3).

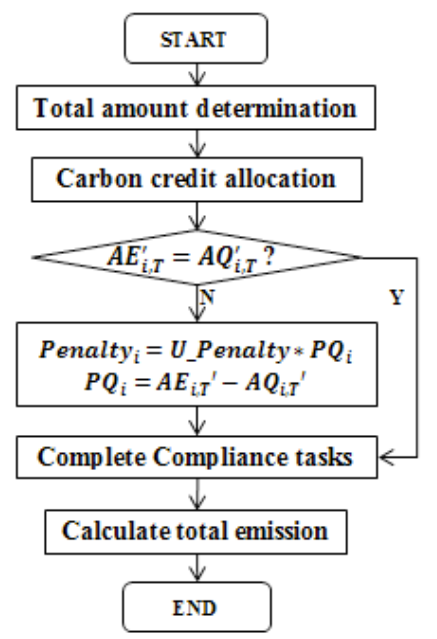

Fig. (3). Flowchart of government behavior.

\subsubsection{The Total Emission Reduction Target and Allow- ances Determination}

At beginning of each period, the government determines the total emission reduction target and allowances after analyzing the national and regional reduction targets, social trends, potential energy saving capability, sector development trends and other factors comprehensively. This part won't be simulated, instead of using the real data.

\subsubsection{Carbon Credit Allocation}

The grandfather rule and bench-marking rule are two of widely used methods in Chinese pilot areas, but it is not exactly the same between different regions. Four types of allocation methods are summarized, considering allowances decline rate, early emission reductions, historical emissions and other factors, as displayed in Fig. (4).

In Fig. (4), $n$ stands for allowance decline rate, $E R_{i}$ represents the early emission reductions, $A v g$ Emission $_{i}$ means the historical emissions of firm i, $B_{i, T}$ and $A v g O u t p u t_{i}$ represent industry benchmark value and historical average output. Different methods can be chosen when simulated, also can be used mixed according to different sectors.

\subsubsection{Allowance Settle}

At the end of each period, government determines whether the firms complete compliance tasks according to the reported emissions and current allowances. The firms fulfill the reduction task only when otherwise will be punished. Then related information in register will be cleared.

\subsubsection{Superovulation Penalty}

Firms fail to pay the same amount of emissions with the current allowances will be imposed penalty and superovulation quota from next period. The penalty and superovulation allowances, as indicated in equation (1).

$$
\left\{\begin{array}{l}
\text { Penalty }_{i}=U P \text { enalty } \times P Q_{i} \\
P Q_{i}=A E_{i, T}{ }^{\prime}-A Q_{i, T}{ }^{\prime}
\end{array}\right.
$$

In the end of each period $T$, the total carbon dioxide emissions will be calculated.

\subsection{Firms}

The behaviors of firms mainly include emission control needs analysis, carbon credit transactions and compliance reporting, as displayed in Fig. (5).

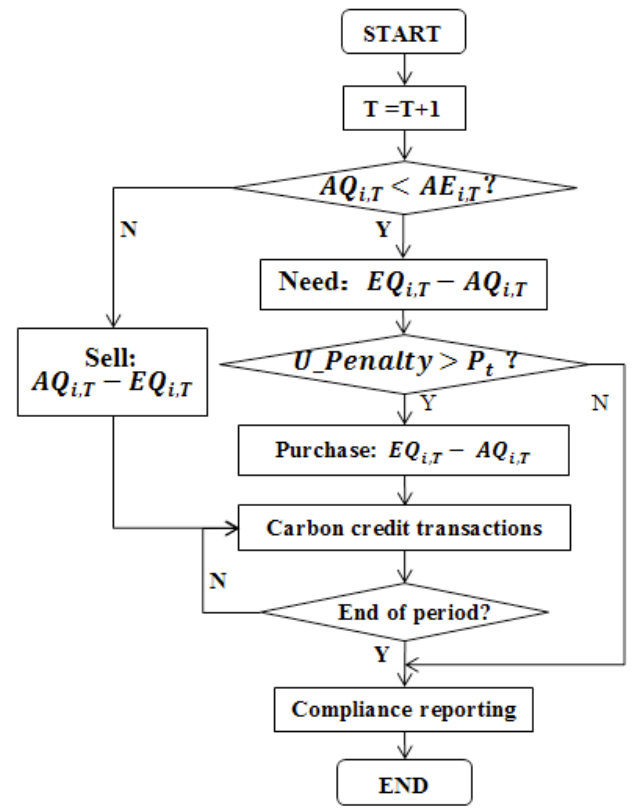

Fig. (5). Flowchart of firm behavior.

\subsubsection{Emission Control Needs Analysis}

The firm $i$ evaluates the current emissions according to historical emissions, and calculates the amount of surplus allowances. Firm i needs to purchase additional carbon credits when, otherwise excess allowances are available for investment or storage to next year. is the trading volume of firm $\mathrm{i}$ in $\mathrm{k}$-th transaction.

\begin{tabular}{ccc}
\hline No & Allocation rule & Annual allowances $A Q_{i, T}$ \\
\hline M1 & Grandfather A & $A Q_{i, T}=$ AvgEmission $_{i} \times(1-n)$ \\
M2 & Grandfather B & $A Q_{i, T}=$ AvgEmission $_{i} \times(1-n)+E R_{i, T}$ \\
M3 & Grandfather C & $A Q_{i, T}=$ AvgEmission $_{i}+E_{i, T}$ \\
M4 & Benchmarking & $A Q_{i, T}=B_{i, T} \times$ AvgOutput $_{i}$ \\
\hline
\end{tabular}

Fig. (4). Four types of allocation methods. 


$$
\left\{\begin{array}{l}
S Q_{i, T}=A E_{i, T}-A Q_{i, T} \\
A Q_{i, T}=A Q_{i, T} \pm T A \text { mount }_{i, k}
\end{array}\right.
$$

\subsubsection{Carbon Credit Transactions}

Under the CET targets, because of the different carbon emissions and allowances between each of firms, the firms with excess allowances become sellers and the one without enough allowances become buyers.

The firms involved in the transaction should determine the quotation and trading volume firstly. The daily initial quotation APrice $_{1}$ depends on the average price of first three trading days, according to equation (3).

$$
A_{-} \text {Price }_{1}=\text { AvgPrice } \times(1 \pm U \sim(0, \alpha))
$$

To successfully matched, the quotation could be adjusted as needed. In general, it will be influenced by the expected price, history average price and other traders' offer. It's also available to wait for the right price. Every mode will be invoked randomly during the simulation.

Firms with surplus allowances have no pressure for lowering emissions, but the ones lacking of allowances are not the case. The trading frequency is affected by the compliance time obviously, and the trading aliveness increases over time.

\subsubsection{Compliance Reporting}

The allowances equal to the actual emissions should be submitted to the government at the specified date; meanwhile, the information will be saved to the register, as described in equation (4).

$$
A E_{i, T}{ }^{\prime}=A E_{i, T}, A Q_{i, T}{ }^{\prime}=A Q_{i, T}
$$

\subsection{Financial and Investment Institutions}

As the special traders in the CET market, financial and investment institutions are not included in the mandatory emission reduction range because of the rare carbon emissions. The behaviors of institutions involve transaction decisions and benefits calculation, as depicted in Fig. (6).

\subsubsection{Transaction decisions}

This category of agents makes their transaction decisions according to the allowance price trends. They behave a clear feature of buying low and selling high. When price is rising, $\Delta P<0$ and $\Delta R>0$, they decide to sell. When price is declining, $\Delta P>0$ and $\Delta R<0$, they make decision of buying. Where is the difference between investor's quoted at time $\mathrm{t}$ and market price at time $t-1$, means the difference between investor's quoted at time $t$ and their unit cost of purchase, as described in equation (5).

$$
\left\{\begin{array}{l}
\Delta P=\text { APrice }_{t}-P_{t-1} \\
\Delta R=\frac{\sum P_{m} \times Q_{m}}{\sum Q_{m}}-\text { APrice }_{t}
\end{array}\right.
$$

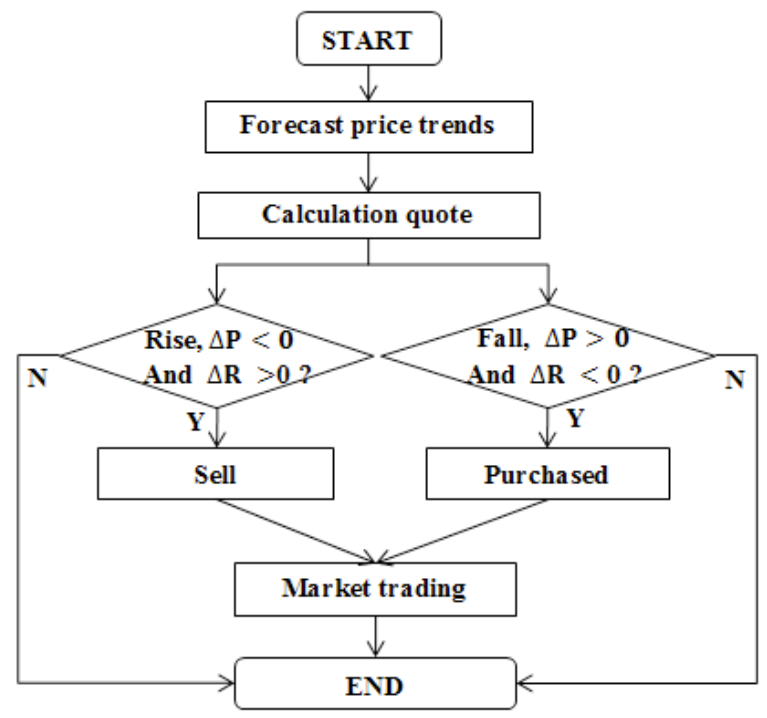

Fig. (6). Flowchart of investment institutions.

\subsubsection{Benefits Calculation}

Interest is the main goal of their participation in the transaction. Investment income is the difference between the total sale and the total purchase, as indicated in equation (6).

$$
R T=\sum P_{m} * Q_{m}-\sum P_{n} * Q_{n}
$$

\subsection{Trading agency}

As the transaction rules maker and information provider, the main behaviors of trading agency involve setting trading rules, managing transactions and providing trading information.

Firms make trading application to the trading agency by delegating declaration. Orders approved would be matched in the trading center, at the same time, the traders' account of quota and funds are frozen. To avoid frequent trading, the $\mathrm{t}+3$ rolling settlement is used in the simulation. Unsuccessful matched orders in that day will be revoked and the corresponding account will be thawed at the end of the day.

In the simulation market, the smallest unit quotation is $0.01 \mathrm{RMB} / \mathrm{t}$, the minimum transaction volume is 1 ton. Constraints are described in equation (7).

$\left\{\begin{array}{l}C P_{d-1} \times(1-\gamma) \leq \text { APrice }_{1} \leq C P_{d-1} \times(1+\gamma) \\ P_{t} \times(1-\gamma) \leq \text { APrice }_{i, t} \leq P_{t} \times(1+\gamma) \\ \text { Amount } \leq \text { MaxAmount }\end{array}\right.$

where means the previous day's closing price, is the proportion of price limits and is the maximum transaction volume.

\subsection{Simulation System Framework}

The proposed CET market model is designed according to the analysis of agents' behavior and rules in reality. To reuse, add and adjust the system function conveniently, a layered architecture is used. The system framework consists of interaction layer, functional layer, model layer and data layer, as display in Fig. (5). To simulate the dynamic behav- 


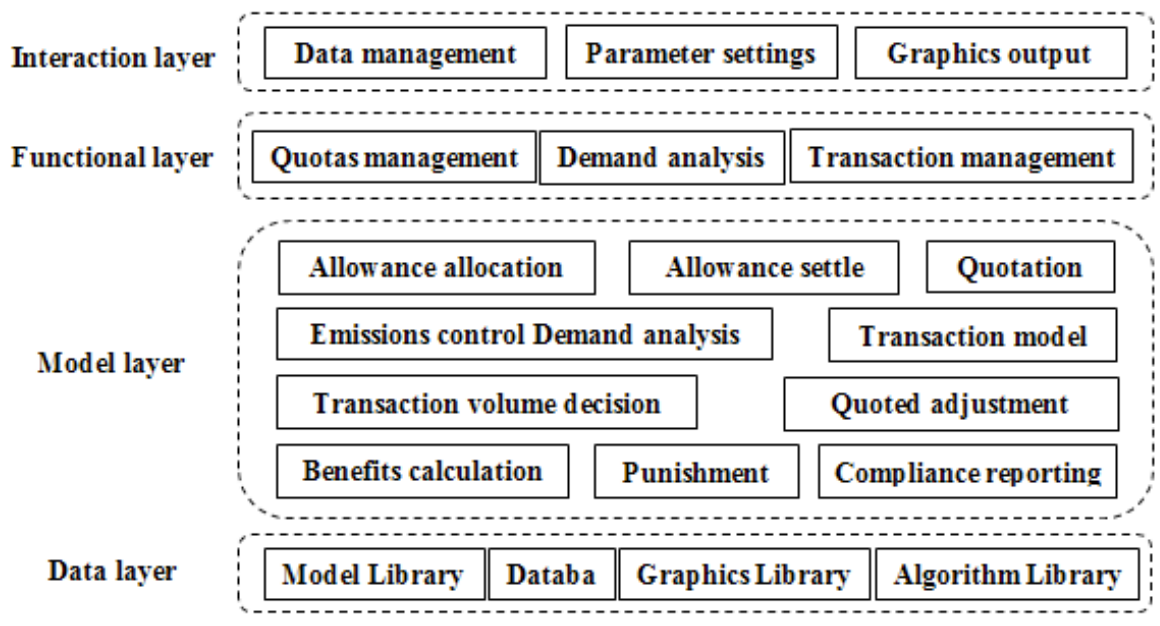

Fig. (7). Architecture of simulation system.

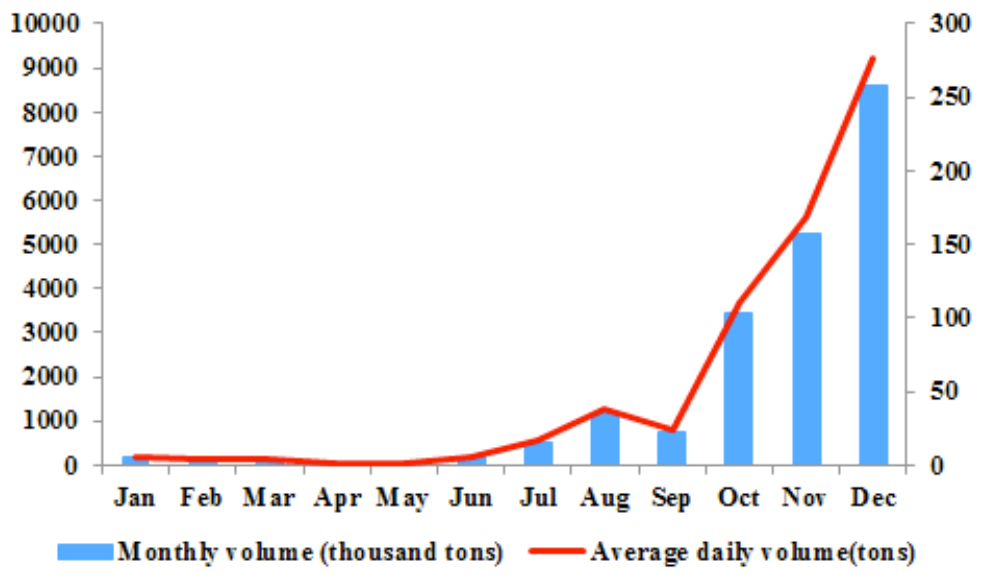

Fig. (8). Simulation market transaction volume trend.

ior of agents in the market much better, a CET market simulation system based on SWARM is established.

The functional layer involves quotas management, emission control management and transaction management. The quotas management module includes allowance allocation, punishment, allowance settle and compliance reporting process. Emission control management module is used to analyze the needs of emission control. Quotations and adjustment, transaction volume determination and benefits calculation process are parts of transaction manage-ment module. Different behaviors of agents are simulated by calling the related models.

\section{RESULTS AND DISCUSSION}

To testify the validity and accuracy of the proposed simulation system, transactions of Shanghai CET market in 2013-2014 year were simulated. Allowance allocations and bidding transactions are simulated, ignoring the transfer agreement, energy conservation and some of other activities. There are 190 firms covered 14 sectors, one government, six investment institutions and one trading agency. The hybrid approach of M3 and M4 are used in simulation, the initial carbon price of $26 \mathrm{RMB} / \mathrm{t}$, valued 100 thousand tons, the proportion of price limits $\gamma$ valued 0.3 , the unit fine valued $100 \mathrm{RMB} / \mathrm{t}$.
A number of simulations are operated to prevent system errors and guarantee the objectivity and accuracy. The simulation results are analyzed as follows:

\subsection{Transaction Volume}

In terms of the transaction volume, the performance of simulation market is dull at the beginning. However, it is gradually going up since August, especially concentrated in November and December, i.e. the compliance period. During this period, the total transaction volume is nearly 415 thousand tons, accounting for $68 \%$ of the total trading volume, as shown in Fig. (8).

\subsection{Transaction Price}

At beginning, the average price I s relatively flat, fluctuating in $22 \mathrm{RMB} / \mathrm{t}$. Since May, it rises slowly, and remains at around $35 \mathrm{RMB} / \mathrm{t}$. From October, the average price maintains more than $40 \mathrm{RMB} / \mathrm{t}$, see Fig. (9).

\subsection{Number of traders}

As for the number of traders, during January to September, the degree of participation is relatively low, basically a seller's market. Since October, the number of participants, especially the buyers, increases rapidly, see Fig. (10). 


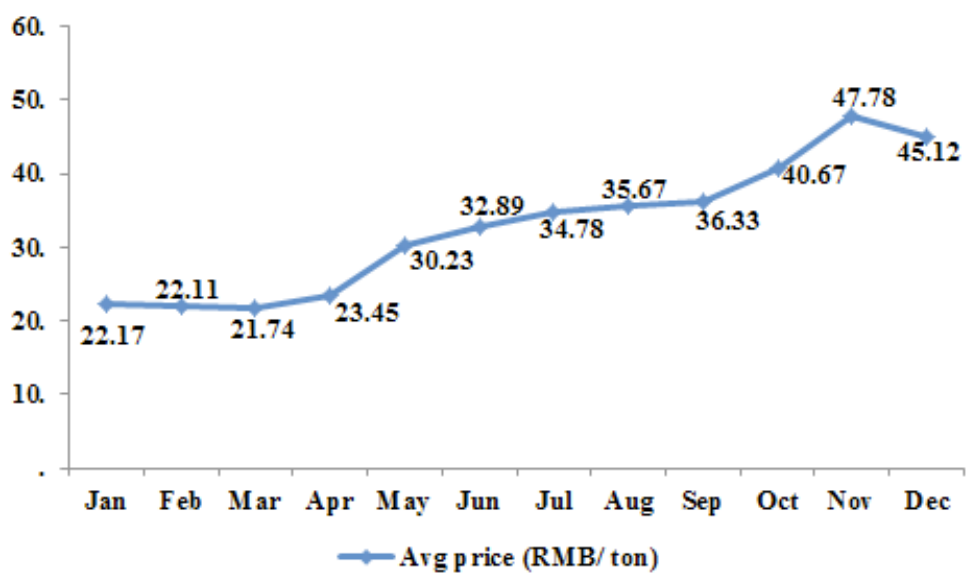

Fig. (9). Simulation market transaction price trend.

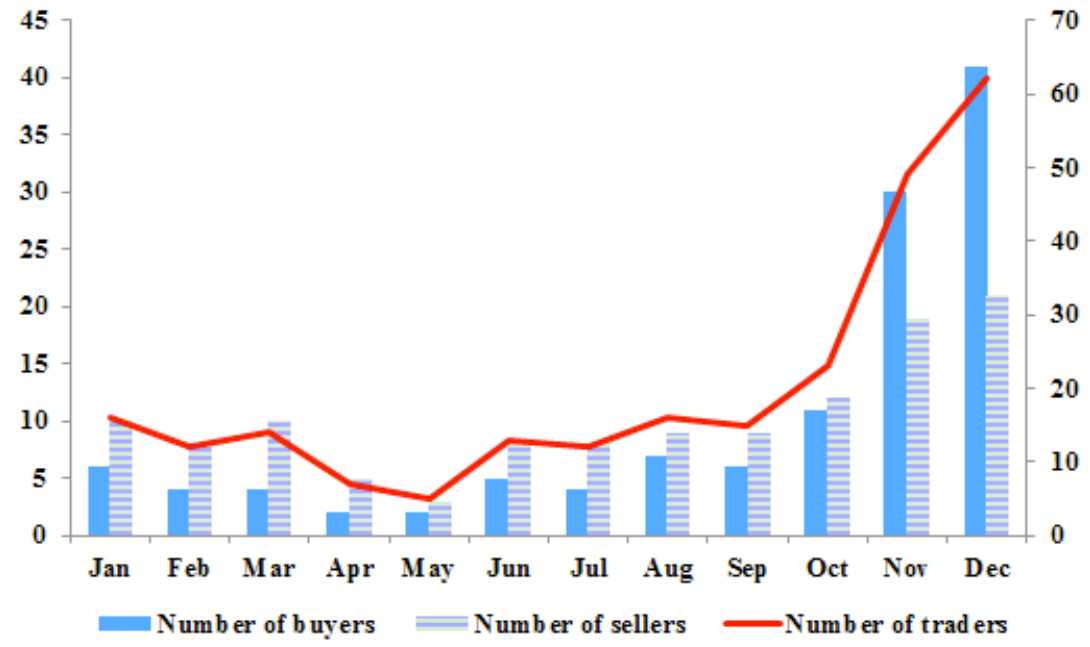

Fig. (10). Market traders in the simulation market.

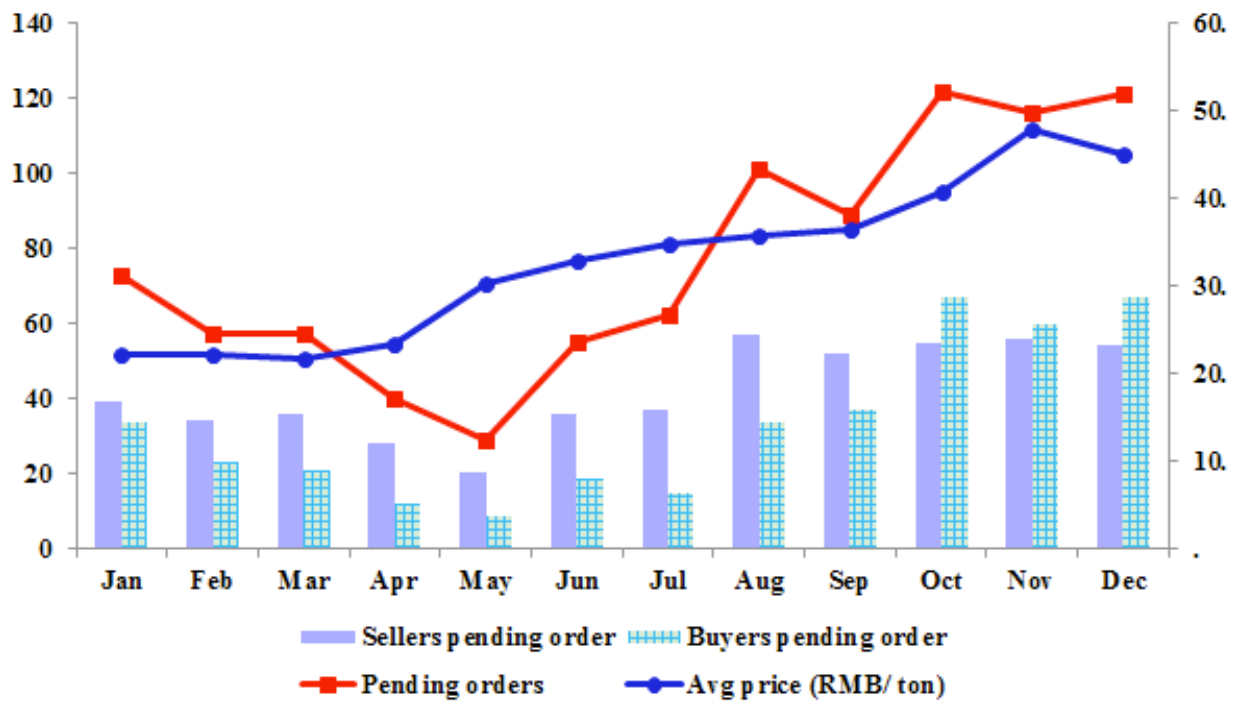

Fig. (11). Simulation market pending orders trends.

\subsection{Number of Pending Orders}

In terms of pending orders, there is a downward trend because of few traders. From January to September, pending orders to buy are less than the ones to sell. Since June, the number of orders increases while the buyers are also growing, and reaching peak in December, see Fig. (11).

Analysis of the overall transaction, monthly transaction volume, price and the number of traders show different de- 


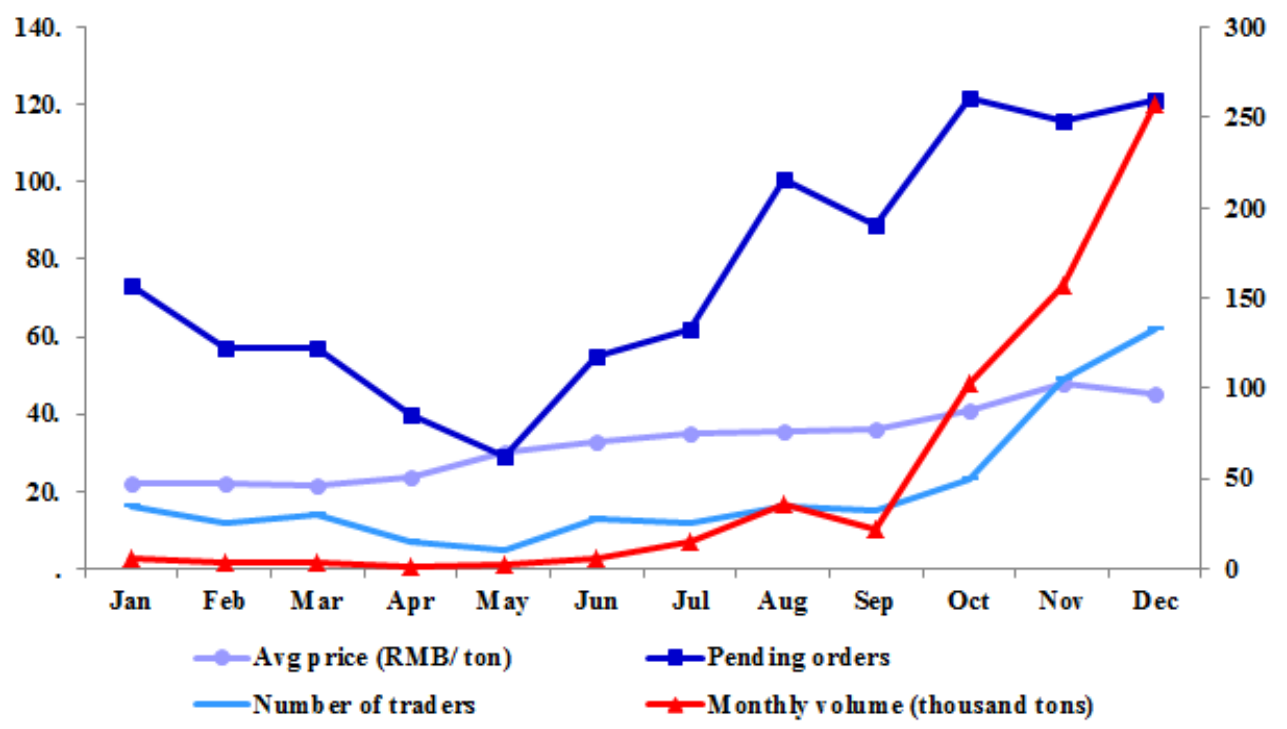

Fig. (12). Simulation market transaction conditions.

grees of increasing, and peak at compliance period (i.e. December) (Fig. (12)). However, the pending orders expand after a period of declining, mainly due to the different proportions of sellers and buyers.

\subsection{System Effectiveness Analysis}

Shanghai CET market is a pilot market. The firms make decisions of transaction only according to their quota surplus. This market is a typical primary market which is dull before the compliance time and then frequent. The statistical data of 2013-2014 annual CET market report published by Shanghai government illustrates this point.

The simulation results of the proposed CET market simulation system are basically consistent with the actual situation. But still there are some differences in transaction volume and the ratio of buyers and sellers. (1) Transaction volume. The total market volume of Shanghai in the first year is 900 thousand tons, which is only 610 thousand tons in simulation market. The reason may be due to neglect of the production market, resulting to deviations of actual emissions, thereby affecting the demand for allowances. (2) The proportion of buyers and sellers. The number of buyers is always more than the number of sellers in Shanghai market, while it is exactly opposite in the simulation system during January to October. It is probably that, issues such as the behavior rules and parameter settings still exist, affecting the participants' decisions. However, in terms of the whole market, the simulation system could run smoothly and the results are similar with the real market of Shanghai, which indicates the accuracy and validity is quite satisfactory.

\section{CONCLUSION}

This paper proposed an agent-based real-time bidding CET market simulation framework involved government, firms, financial and investment institutions and trading agency four kinds of agents. The simulation results of Shanghai market investigate the reliability of this system. It could be used as a general-purpose system to study the dif- ferent factors and how they affect the CET market in the future. CET market is a part of the whole economic system, future studies will focus on the production market, raw materials market, energy service market, and how they interact with each other.

\section{CONFLICT OF INTEREST}

The authors confirm that this article content has no conflict of interest.

\section{ACKNOWLEDGEMENTS}

This research work was supported by the National Natural Sciences Foundation of China (No.70921001), the National Natural Sciences foundation of China (No.71431006) and the National Natural Sciences Foundation of China (No.71271216).

\section{REFERENCES}

[1] F. Mutlu, and F. N, "Agent based simulation of carbon emissions trading market," Technology Management in the Energy Smart World, pp. 1-10.

[2] J. Stańczak, "Agent-based evolutionary method of simulation the $\mathrm{CO}_{2}$ emission permits market," Foundations of Computing and Decision Sciences, vol. 38, no. 4, 2013.

[3] Y. Liu, "Relationship between industrial firms, high-carbon and low-carbon energy: An agent-based simulation approach," Applied Mathematics and Computation, vol. 219, no. 14, pp. 7274, 2013.

[4] E.J.L. Chappin, (ed.) "An agent-based model of the system of electricity production systems: exploring the impact of $\mathrm{CO}_{2}$ emissiontrading,"IEEE International Conference on System of Systems Engineering, pp. 1-6, 2007.

[5] R. Cong, and Y. Wei, "Potential impact of (CET) carbon emissions trading on China's power sector: A perspective from different allowance allocation options," Energy, vol. 35, no. 9, pp. 3921-3931, 2010.

[6] Z. LIU, (ed.) "Simulation study on operation mode of low-carbon electricity market,"Power System Technology, vol. 37, no. 3, pp. 604-609, 2013.

[7] J. W7ang, (ed.) "An agent-based approach to modeling interactions between emission market and electricity market," Power \& Energy Society General Meeting, pp. 1-8,2009. 
[8] H. Deng, (ed.) "Multi-agent based simulation of carbon emissions trading market in China," Service Systems and Service Management(ICSSSM), pp. 686-691, 2013.

[9] L. Tang, (ed.) "Carbon emissions trading scheme exploration in China: A multi-agent-based model," Energy Policy, vol. 1, pp. 152169, 2015.

[10] B. Anderson, and C. Maria, "Abatement and allocation in the pilot phase of the EU ETS," Environ Resource Econ, vol. 48, no. 1, pp. 83-103, 2011.

[11] Z. Bing, (ed.) "Policy Design and Performance of Emissions Trading Markets: An Adaptive Agent-Based Analysis," Environ-mental Science \& Technology, vol. 44, no. 15, pp. 5693-5699, 2010.
[12] A. D. Ellerman, and B. K. Buchner, "Over-allocation or abatement? A preliminary analysis of the EU ETS based on the 2005-06 emissions data," Environ Resource Econ, vol. 41, no. 2, pp. 267-287, 2005.

[13] H. LI, and D. ZHAO, "Multi-agents based modeling and simulation for carbon permits trading," Computer Engineering and Applications, vol. 48, no. 25, pp. 9-14, 2012.

[14] H. Mizuta, and Y. Yoshiki, "Agent-based simulation and greenhouse gas emissions trading," Tokyo Research Laboratory, Simulation Conference, pp. 535-540, 2001.

(C) Dong-Bin et al.; Licensee Bentham Open.

This is an open access article licensed under the terms of the (https://creativecommons.org/licenses/by/4.0/legalcode), which permits unrestricted, noncommercial use, distribution and reproduction in any medium, provided the work is properly cited. 